\title{
Experimental issues at ultrasonically aided micro-EDM of CoCr alloys
}

\author{
Niculae Marinescu, Daniel Ghiculescu*, and Claudiu Pirnau \\ "Politehnica" University of Bucharest, Manufacturing Engineering Department, 313 Splaiul \\ Independentei, Bucharest, Romania
}

\begin{abstract}
The paper deals with researches of microtopography obtained at different working modes at ultrasonically aided micro-electrical discharge machining $(\mu \mathrm{EDM}+\mathrm{US})$ and pure micro-EDM, using both commanded and relaxation pulses. Images of machined surface taken with scanning electron microscope were analyzed in correlation with chemical composition of samples detected by $\mathrm{X}$ rays spectrometer. This led to some explanations of material removal mechanism, aiming at improvement of process modelling and performances increase of $\mu \mathrm{EDM}+\mathrm{US}$.
\end{abstract}

\section{Introduction}

The exceptional properties of CoCr alloys made them matter of utilization in many areas. High stiffness, high surface quality, extremely wear-resistant and corrosion resistant in lactic acid and sodium chloride and also biocompatibility $[1,2]$ recommend their use in medical applications as material for knee implants, metal-to-metal hip joints, fixation devices for fractured bones, and dental prosthetics. Under these conditions, fractures should be attributed generally to incorrectly designed clasps, or to stress concentration areas, and not to material mechanical characteristics [1].

The existence of $\mathrm{Ni}$ in $\mathrm{CoCr}$ alloys composition allows the utilization as fuel nozzles and vanes for industrial gas turbines. High hardness and excellent surface quality permit utilization at injection molding of plastic parts [2].

There are also several types of stellite superalloys, belonging to the $\mathrm{CoCr}$ ones, having variable content of: Ti, Si, S, P, Mo, W, Mg, Cr, Co, B, Al, Fe, and Ni. Due to their high mechanical properties, these alloys are used in different industrial applications like: valves, valve seats for internal combustion engines, machine gun and machine gun barrels, artificial hip joints, other bone replacements, dental prosthesis, and cutting tools. The $\mathrm{C}$ content and as a result, carbides volume within stellite alloys decisively influences the material performances. Therefore, the following classification of these alloys is possible: high $\mathrm{C}$ content - for high wear applications; low $\mathrm{C}$ content - for high temperature use; low $\mathrm{C}$ / higher Cr content for corrosion resistance [3, 4].

But $\mathrm{CoCr}$ alloys mechanical properties determine consistent difficulties at machining, especially when carbides are present in their structure, and complex surfaces are generated by micromachining. Ultrasonically aided electrical discharge machining (EDM+US) could

*Corresponding author: daniel.ghiculescu@upb.ro 
be a competitive response of all these, in terms of machining rate, precision and surface quality in relation with manufacturing costs [5]. Other advanced materials, difficult to process with other means, were machined by EDM+US with spectacular increase of main technological performances $[6,7,8]$, but no reported references for $\mathrm{CoCr}$ alloys yet [9].

\section{Experimental setup}

In order to study the micro-EDM+US process on $\mathrm{CoCr}$ alloy, an experimental setup was created, presented in Fig. 1. Sheet samples of 30 x 50 x $1 \mathrm{~mm}$ were machined comparatively on Romanian ELER 01 machine with $20 \mathrm{kHz}$ longitudinal ultrasonic oscillations of toolelectrode (EDM+US), and without US (classic EDM). The device for clamping the ultrasonic chain, which included the tool at its end, is a granted patent [10].

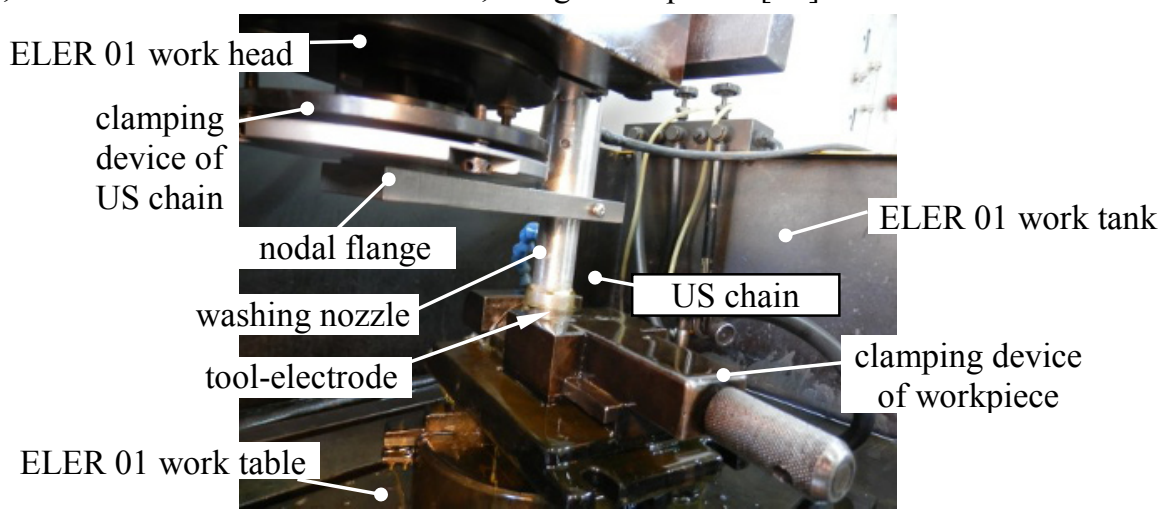

Fig. 1. Technological system elements for EDM+US micromachining of CoCr alloy samples.

Some preliminary tests on this $\mathrm{CoCr}$ alloy were done using both commanded and relaxation pulses provided by a special generator dedicated to finishing and micromachining, connected to ELER 01 machine. The working parameters at commanded pulses were: current step, $I=3 \mathrm{~A}$, positive (tool) polarity, lateral flushing with pressure, $p_{h l}=0.04$ $\mathrm{MPa}$, pulse time $t_{i}=48 \mu \mathrm{s}$, pause time, $t_{0}=24 \mu \mathrm{s}$ - working mode no. $1 ; t_{i}=8 \mu \mathrm{s}, t_{0}=8 \mu \mathrm{s}$-working mode no. 2. At relaxation pulses, the specific working parameters were used: negative polarity, capacitor step, $C=10 \mathrm{nF}$, resistance step, $R=0.74 \mathrm{k} \Omega$ (for adjusting supply current) working mode no. 3. At $\mu \mathrm{EDM}+\mathrm{US}$, the consumed power on ultrasonic chain $\left(P_{c U S}\right)$ was 90 , $120 \mathrm{~W}$.

The variation of total hydraulic pressure $\left(p_{h t}\right)$ in the gap was determined by elongation $(z)$, according to relation:

$$
p_{h t}=2 \pi c \rho f_{U S} z+p_{h l} \quad[\mathrm{~Pa}],
$$

where: $c$ is sound velocity in dielectric liquid $[\mathrm{m} / \mathrm{s}] ; \rho$ - dielectric liquid density $\left[\mathrm{kg} / \mathrm{m}^{3}\right] ; f_{U S}$ - ultrasonic frequency [Hz]; $z$ - elongation, $z=A \sin \omega t ; A$ - amplitude $[\mathrm{m}] ; \omega=2 \pi f_{U S}\left[\mathrm{~s}^{-1}\right] ; p_{h l}$ - local hydraulic pressure [Pa]. In this case, the values of parameters were: $p_{h l}=0.04 \mathrm{MPa}$, $\rho=840 \mathrm{~kg} / \mathrm{m}^{3}$ (P3 dielectric liquid), $K=1.35 \times 10^{9} \mathrm{~Pa}(K$-bulk modulus $), c=(K / \rho)^{1 / 2}=1267.7 \mathrm{~m} / \mathrm{s}$, $A=2 \mu \mathrm{m}, f_{U S}=20 \mathrm{kHz}$.

A collective implosion of gas bubbles, generating shock waves occurs at each final of ultrasonic period $T_{U S}$. This is called the cumulative microjets stage (CMS), generating pressure of $100 \mathrm{MPa}$ order of magnitude, oriented horizontally along the frontal gap. This is able to reduce the surface roughness by removing by shearing the peaks of microgemetry. The work parameter related to ultrasonic pressure is the consumed power on ultrasonic chain, including the tool $\left(P_{c U S}\right)$. 
The commanded or relaxation pulses are delivered during ultrasonic oscillations of tool-electrode. Experimentally, it was noticed that at overlapping the pulses on CMS, the discharge is stopped, hence dielectric liquid accesses the melting material by discharge since the gas bubble formed around plasma channel collapses.

\section{Analysis of chemical composition and microtopography}

The chemical composition of machined samples (cast and cold-worked) was determined by $\mathrm{X}$ rays spectrometer energy dispersive (EDS) with resolution at MnK of $133 \mathrm{eV}$ - table 1 . It can be noticed close values of weight $\%$ for $\mathrm{Co}, \mathrm{Cr}$ and Mo in case of all used samples, the $\mathrm{C}$ content being under $0.1 \%$. Therefore, three different working modes, EDM and EDM+US, were applied on very close chemical composition of the samples no. 1,2 and 3 because their surfaces were so small to have three different machined marks on each of them.

Table 1. Chemical composition of $\mathrm{CoCr}$ alloy samples.

\begin{tabular}{|c|c|c|c|}
\hline Element & $\begin{array}{c}\text { Sample no. 1, } \\
\text { weight \% }\end{array}$ & $\begin{array}{c}\text { Sample no. 2, } \\
\text { weight \% }\end{array}$ & $\begin{array}{c}\text { Sample no. 3, } \\
\text { weight \% }\end{array}$ \\
\hline $\mathrm{Si}$ & 0.7 & 0.68 & 0.68 \\
\hline $\mathrm{Cr}$ & 26.72 & 27.48 & 27.61 \\
\hline $\mathrm{Co}$ & 58.09 & 59.6 & 57.28 \\
\hline $\mathrm{Mo}$ & 14.49 & 12.42 & 14.12 \\
\hline
\end{tabular}

Investigation of machined samples microtopography was made by scanning electron microscope QUANTA INSPECT F50, provided with field emission electron gun with resolution of $1 \mathrm{~nm}$.

The images of machined microtopography obtained at pure $\mu \mathrm{EDM}$ with working mode no.1, and sample no.1 are presented in Fig. 2:
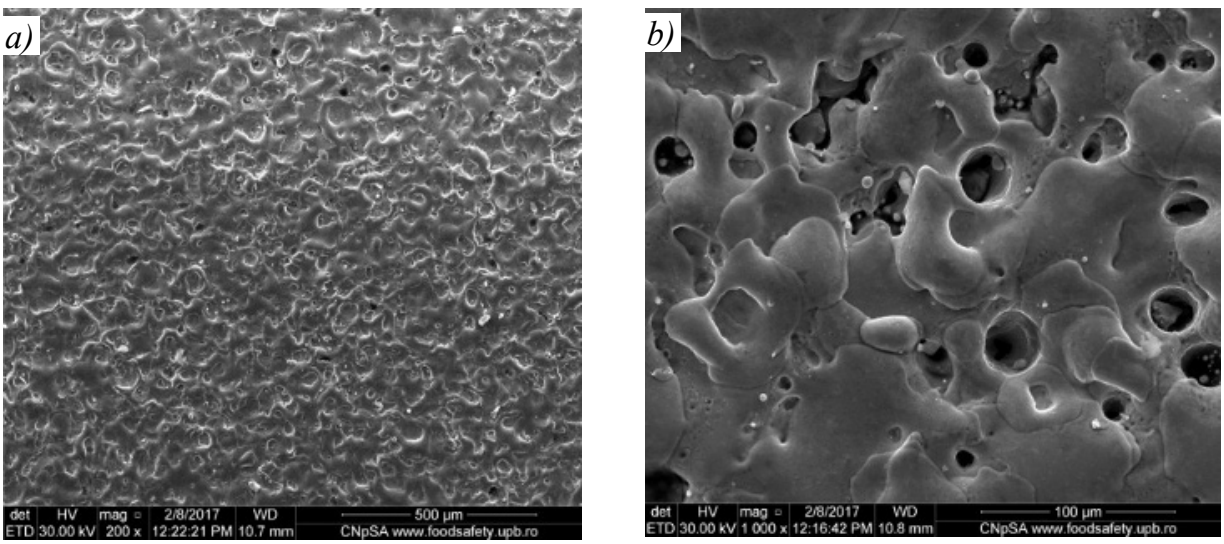

Fig. 2. Microtopography at $\mu \mathrm{EDM}, I=3 \mathrm{~A}, t_{i}=48 \mu \mathrm{s}, t_{0}=24 \mu \mathrm{s}$, polarity +; (a) general; (b) detail view.

The roughness of machined surface was $R a=2.2 \mu \mathrm{m}$, determined by SJ411 surface instrument. The average of craters transversal dimensions was $D_{c r}=22 \mu \mathrm{m}$.

At $\mu$ EDM+US with working mode no.1, on sample no.1, with consumed power on US chain, $P_{c U S}=120 \mathrm{~W}$, the images of machined microtopography are presented in Fig. 3. 

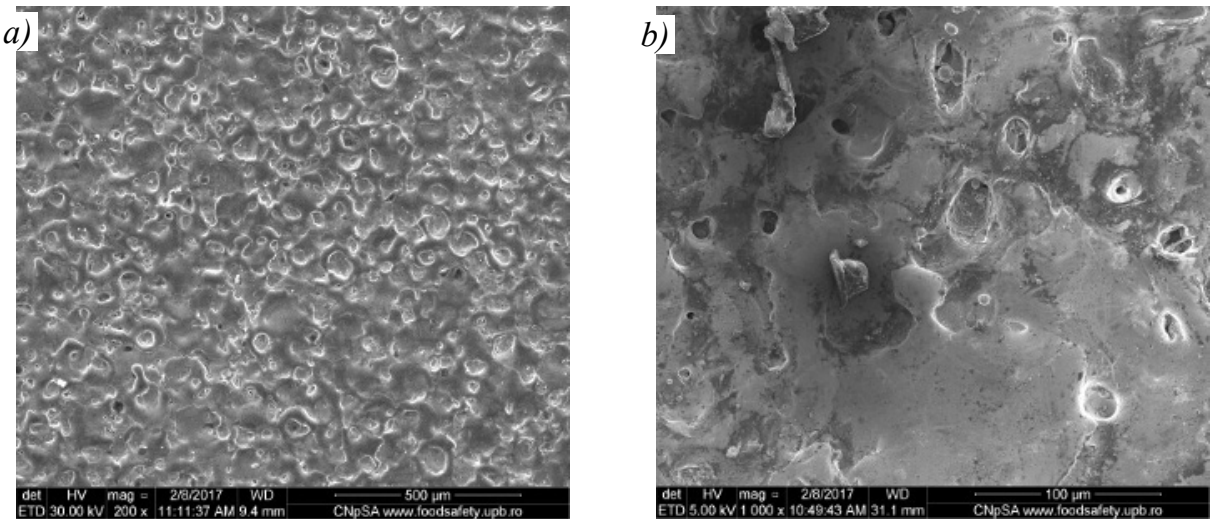

Fig. 3. Microtopography at $\mu \mathrm{EDM}+\mathrm{US}, I=3 \mathrm{~A}, t_{i}=48 \mu \mathrm{s}, t_{0}=24 \mu \mathrm{s}$, polarity $+; P_{c U S}=120 \mathrm{~W}$; (a) general view; (b) detail view.

In this case, the sample roughness was $R a=2.4 \mu \mathrm{m}$, and the average of craters transversal dimensions was $D_{c r}=26 \mu \mathrm{m}$. As it can be noticed, at relative high value $P_{c U S}=120 \mathrm{~W}$, an increase of crater volume is produced due to ultrasonic aiding not only in terms of crater diameter but also in depth.

A specific phenomena also occurred: a smaller crater is often developed in a greater crater as it is emphasized in Fig. 4, probably as a result of cavitational phenomenon ultrasonically induced - a gas bubble collapsing inside of a main crater produced by electrical discharge.

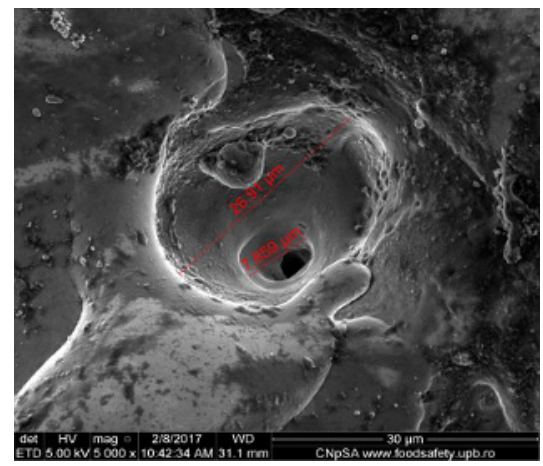

Fig. 4. Microtopography of smaller crater within a main crater at $\mu \mathrm{EDM}+\mathrm{US}, I=3 \mathrm{~A}, t_{i}=48 \mu \mathrm{s}, t_{0}=24$ $\mu \mathrm{s}$, polarity $+; P_{c U S}=120 \mathrm{~W}$.
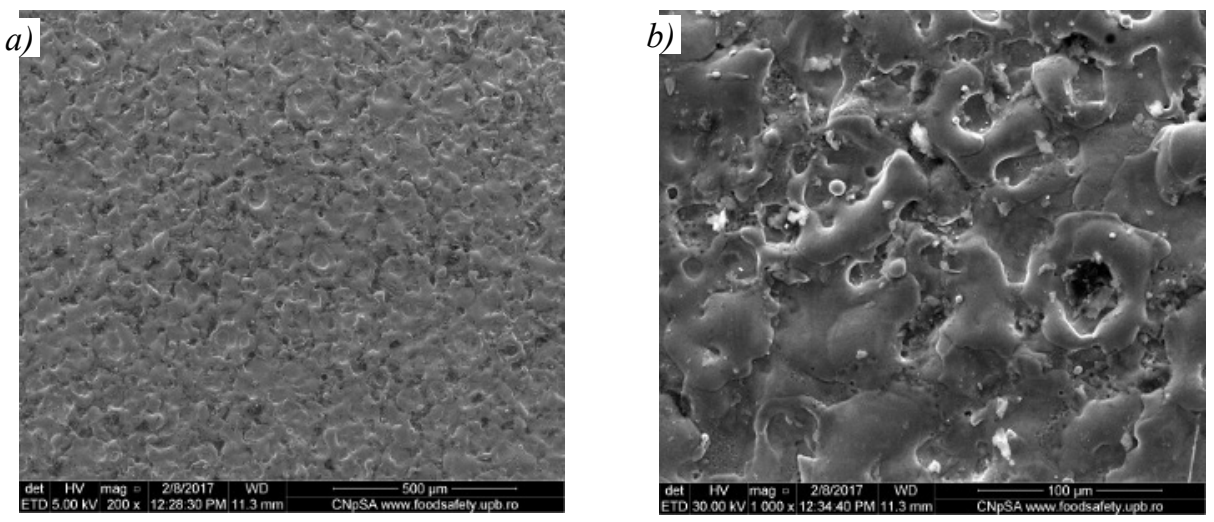

Fig. 5. Microtopography at $\mu \mathrm{EDM}, I=3 \mathrm{~A}, t_{i}=8 \mu \mathrm{s}, t_{0}=8 \mu \mathrm{s}$, polarity + ; (a) general; (b) detail view. 
a)

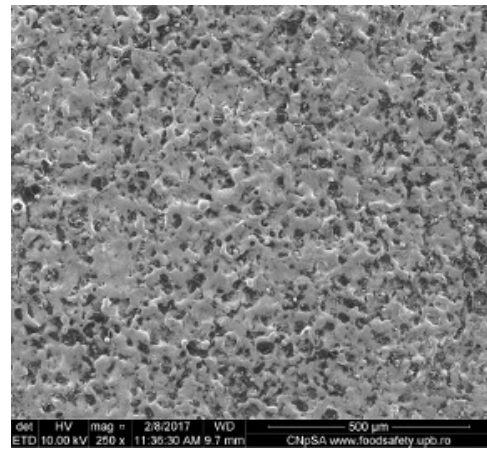

b)

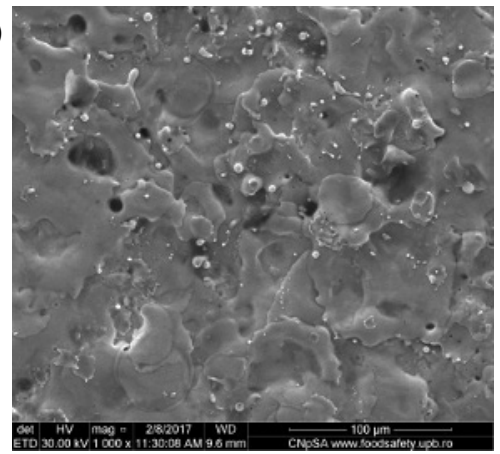

Fig. 6. Microtopography at $\mu \mathrm{EDM}+\mathrm{US}, I=3 \mathrm{~A}, t_{i}=8 \mu \mathrm{s}, t_{0}=8 \mu \mathrm{s}$, polarity,$+ P_{c U S}=90 \mathrm{~W}$ : (a) general; (b) detail view.

The images of machined microtopography obtained at pure $\mu$ EDM with working mode no. 2, on sample no. 2, are presented in Fig. 5. The sample roughness was $R a=1.6 \mu \mathrm{m}$, and the average of craters transversal dimensions was $D_{c r}=18 \mu \mathrm{m}$.

At $\mu \mathrm{EDM}+\mathrm{US}$ and the same working mode, no. 2, sample no. 2, with lower power consumed on the US chain, $P_{c U S}=90 \mathrm{~W}$, than in previous case, the microtopography is shown in fig. 7. The sample roughness was $R a=1.2 \mu \mathrm{m}$, and the average of craters transversal dimensions was $D_{c r}=16 \mu \mathrm{m}$. As it can be noticed comparing figures 5.b and 6.b a certain levelness of machined surface was obtained through US assistance at lowering of $P_{c U S}$.

At $\mu$ EDM with relaxation pulses, working mode no. 3 , on sample no. 3 , the images of microtopography are presented in Fig. 7. The sample roughness was $R a=0.8 \mu \mathrm{m}$, and the average of craters transversal dimensions was $D_{c r}=13 \mu \mathrm{m}$.

a)

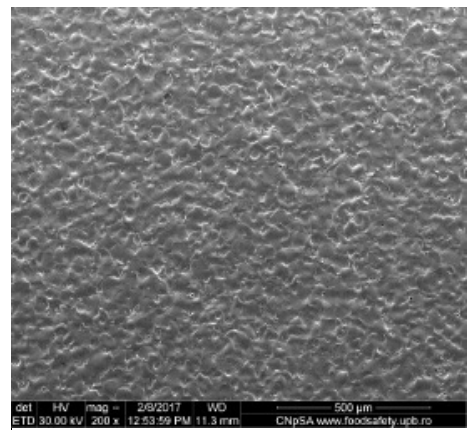

b)

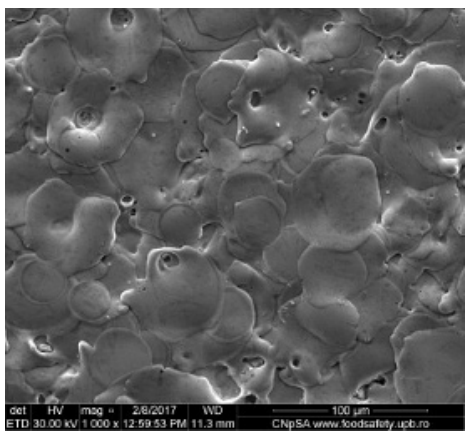

Fig. 7. Microtopography at $\mu \mathrm{EDM}, C=10 \mathrm{nF}, R=0.74 \mathrm{k} \Omega$, polarity - ; (a) general; (b) detail view.

a)

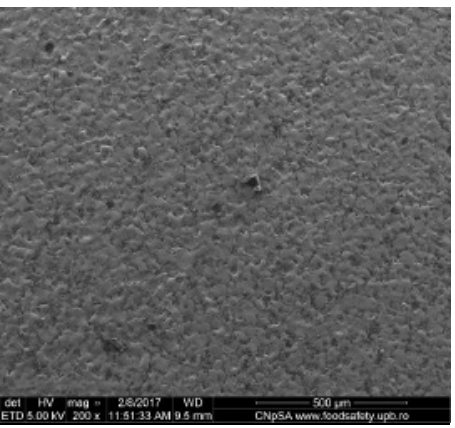

b)

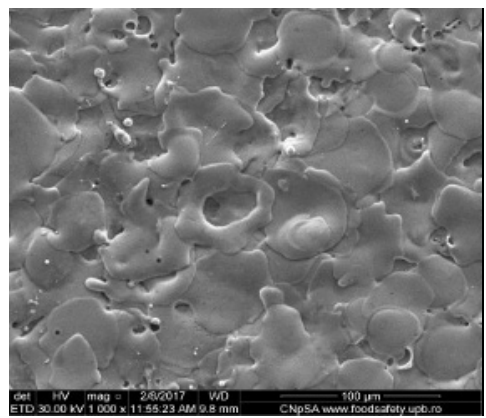

Fig. 8. Microtopography at $\mu \mathrm{EDM}+\mathrm{US}, C=10 \mathrm{nF}, R=0.74 \mathrm{k} \Omega$, polarity -, $P_{c U S}=90 \mathrm{~W}$ : (a) general view; (b) detail view. 
At $\mu$ EDM+US with relaxation pulses, working mode no. 3 , on sample no. 3 , with $P_{c U S}=$ $90 \mathrm{~W}$, the images of microtopography are presented in Fig. 8. In this last case, the sample roughness was $R a=0.6 \mu \mathrm{m}$, and the average of craters transversal dimensions was $D_{c r}=10$ $\mu \mathrm{m}$. As it can be noticed, keeping relative low value of $P_{c U S}$, the surface roughness was also decreased as well as craters transversal dimensions.

\section{Conclusions}

Analyzing the microtopography of $\mathrm{CoCr}$ alloy samples, one can observe that crater average dimensions are increased as the discharge energy increases (in this order, working modes no. 1, 2, 3), the variation of samples chemical composition, which is very small, having insignificant influence.

At lower values of the power consumed on ultrasonic chain $\left(P_{c U S}\right)$ in case of ultrasonically aided micro-electrical discharge machining ( $\mu \mathrm{EDM}+\mathrm{US})$, the craters transversal dimensions are decreased. On the contrary, at higher values, these are increased. This effect is the result of crater margins removal, since they are more sensitive of ultrasonic shock waves produced by cavitation, oriented parallel to the working gap direction.

The ultrasonic aiding is able to reduce the roughness of machined surface of $\mathrm{CoCr}$ alloy samples, resulted from micro-EDM if the power $P_{c U S}$ has optimum value. At higher $P_{c U S}$ values, the surface roughness is increased, together with craters transversal dimensions. In this case, it was also observed a specific microgeometry, e. g. smaller craters in main EDM craters, probably produced by ultrasonically induced cavitation within the working gap, which could also increase the machining rate spectacularly.

After these preliminary researches of $\mu \mathrm{EDM}+\mathrm{US}$ applied on $\mathrm{CoCr}$ alloy, further researches will be developed in order to draw the variation of craters dimensions with respect to consumed power on ultrasonic chain, and on this base, to find the optimum value of this parameter, leading to minimum surface roughness.

The paper was achieved in Joint Applied Research Project supported by MEN-UEFISCDI, project no. PN-II-PT-PCCA-2013-4-0236, Contract no. 222/2014. The SEM analyzes/images obtained on the samples were possible due to EU-funding project POSCCE-A2-O2.2.1-2013-1/Prioritary Axe 2, Project No. 638/12.03.2014, ID 1970, SMIS-CSNR code 48652.

\section{References}

1. Y. S. Al Jabbari, J. Adv. Prosthodont. 6, 138-145 (2014)

2. *** Arcam AB, ASTM F75 CoCr Alloy, 3 (2010)

3. S. Kapoor, R. Liu, X. J. Wu, M. X. Yao, Int. J. Ch. M. Nucl. Mat. Met. Eng. 6, 592-601 (2012)

4. $* * *$ Hardfacing Alloys 22, kennametal.com/stellite (2016)

5. M. P. Jahan, et al., Electrical Discharge Machining (EDM). Types, Technologies and Applications (Nova, New York, 2015)

6. C. Praneetpongrung, Y. Fukuzawa, S. Nagasawa, et al., Mat.Trans., 51, 2113-2120 (2010)

7. M. Iwai, S. Ninomiya, K.Suzuki, Procedia CIRP, 6, 146-150 (2013)

8. Z. Qinjian, Z. Luming, L. Jianyong, et al., Procedia CIRP, 6, 589-593 (2013)

9. B. C. Khatri, P. Rathod, J. B. Valaki, J. Eng.Manuf., 1, 1-12 (2015)

10. D. Ghiculescu, N.I. Marinescu, S. Nanu, Romanian granted patent, RO-126191 (2012) 